\title{
OTIF KAIN TAIS TIMOR SEBAGAI SUMBER INSPIRASI PENCIPTAAN BUSANA PESTA
}

\author{
Libania Maria Flor Sarmento
}

\begin{abstract}
ABSTRACK
ABSTRAK

Kain tenun bagi masyarakat Timor dapat menunjukkan suatu status sosial yang tinggi. Kaum bangsawan Pemilikan biasanya mewariskan kain tenun kepada generasi berikutnya. Kainkain tenun yang paling tinggi nilainya diperlihatkan pada acara-acara perkawinan dan upacara adat lainnya. Dalam upacara perkawinan juga terjadi pertukaran kain-kain tenun adat dari pihak keluarga laki-laki dengan pihak keluarga perempuan. Kain tenun juga mempunyai nilai yang menentukan dalam aturan adat. Apabila ada pelanggaran terhadap aturan adat, akan dikenakan pembayaran denda yang harus dibayar dengan kain-kain adat. Peralatan tenun yang dipergunakan adalah alat tenun tradisional yaitu alat tenun gedongan.

Terwujudnya karya seni merupakan visualisasi dari pikiran seorang seniman yang memiliki ekspresi jiwa dan diungkap dari suatu pemahaman yang diserap dalam pikiran maupun perasaan. Lewat pemahaman dari berbagai model yang diserap dalam pikiran maupun erasaan akan menimbulkan ide-ide baru yang tak terbatas, kemudian divisualiasiskan lewat simbolsimbol tertentu ke dalam wujud karya seni.

Dalam data-data yang terkumpul, terdapat beberapa bentuk motif yang telah distilir dan dipergunakan untuk tujuan yang berbeda-beda.Untuk tujuan fungsional, motif telah distilir dalam hal hias-menghias pada pakaian dan acesoris, perhiasan dan lainnya.Selain itu, Untuk tujuan seni, motif tradisional Timorbelum pernah distilir dalam hal berkarya seni.
\end{abstract}

Kata kunci : Motif , Tais Timor, kriya Seni.

\section{PENDAHULUAN}

Kain Tenun ikat merupakan salah satu bentuk seni kerajinan tradisional yang dapat kita temui diberbagai daerah yang jumlahnya sangat banyak dan bervariasi untuk tiap-tiap daerah. berdasarkan persebaran asal-usul kebudayaan Indonesia yang di mulai dari jaman Prasejarah pada periode Neolitikum dari Asia Tenggara yang terjadi sekitar 2000 tahun sebelum Masehi.
Penyebaran tenun ikat di Indonesia antara lain terdapat di Rongkong dan Galumpang, Tanah Toraja, Sulawesi Selatan, Bentenan dan Rantahan di Bintik, Minahasa Sulawesi Utara, di Sumatra antara lain di Tanah Batak, Sumatra Utara. kemudian Kalimantan terutama di daerah pedalaman di Kalimantan Barat, Tengah dan Timur termasuk Dayak Iban di daerah Serawak, Malaysia Timur.

\footnotetext{
* Libania Maria Flor Sarmento, Mahasiswa Jurusan Kriya, Fakultas Seni Rupa, Institut Seni Indonesia Yogyakarta
} 
Di Nusa Tenggara Timur di Sumba, Flores, Sawu, Roti, Ndao, Lomblen dan Timor.Pulau Timor yang terbesar di wilayah Nusa Tenggara Timur yaitu Timor. Wilayah Timor ini mempunyai ciri-ciri alam yang terdiri dari padang savana yang luas yang di kelilingi deretan bukit-bukit dengan gunung-gunung serta hutan-hutan primer dan sekunder. Penduduk Timor mempunyai penduduk dari berbagai suku bangsa yang berbeda adat-istiadat maupun sistem kemasyarakatannya.Kelompok yang dominan, adalah orang Helon, orang Antoni, orang Tetun dan orang Mambai.Orang Roti dan Sawu yaitu penduduk yang berasal dari pulau didekat nya yang kemudian banyak diantaranya kemudian menetap di Timor.

Republic Demokratika Timor leste atau di sebut juga Timor Lorasae yang sebelum merdeka bernama Timor-Timur adalah sebuah Negara kecil di sebelah utara Australia dan bagian timur pulau Timor. Selain itu wilayah Negara ini juga meliputi pulau kambing Atauro,Jaco,dan Enclave Oecussi-Ambeno di timur barat. Dengan mata pencarian penduduk pada umum-nya berladang dan berternak selain itu mengerjakan kerajinan tangan antara lain anyam-anyaman,membuat hiasan dari perak,ukir-mengukir dan yang terpenting menenun, pekejaan satu ini khusus di kerjakan oleh kaum wanita yang sudah berkeluarga dan yang belum berkeluarga.menenun hasil tenunan digunakan atau dipake untuk memenuhi kebutuhan mereka sendiri atau diperjual belikan keluar Timor oleh tengkulak kain tenun timor merupakan salah satu seni kerajinan tangan tangan turun-temurun yang di ajarkan kepada anak cucu demi kelestarian seni tenun tersebut.

Kain tenun merupakan salah satu kebutuhan atau perlengkapan hidup manusia yang sudah di kenal sejak zaman prasejarah yang di peroleh dari perkembangan pakian penutup badan setelah rumput - rumputan dan kulit kayu .kain tenun ikat yang merupakan perkembangan dari bentuk kain tenun yang di beri ragam hias ikat diciptakan untuk melengkapi kebutuhan dasar pangan dan tempat tinggal. kain tenun yang cara pembuatan motifnya menggunakan tenun ikat.teknik ikat dilakukan dengan mengikat bagian-bagian tertentu pada benang sehinga bagian tersebut tidak berwarna waktu benang dicelup kedalam zat pewarna bagian-bagian di perhitungkan sedemikian rupa sehingga setelah ditenun akan membentuk motif tertentu.

Kain tenun bagi masyarakat Timor dapat menunjukkan suatu status sosial ang tinggi. Kaum bangsawan Pemilikan biasanya mewariskan kain tenun kepada generasi berikutnya.Kain-kain tenun yang paling tinggi nilainya diperlihatkan pada acaraacara perkawinan dan upacara adat lainnya. Dalam upacara perkawinan juga terjadi pertukaran kain-kain tenun adat dari pihak keluarga laki-laki dengan pihak keluarga perempuan.Kain tenun juga mempunyai nilai yang menentukan dalam aturan adat. Apabila ada pelanggaran terhadap aturan adat, akan dikenakan pembayaran denda yang harus dibayar dengan kain-kain adat. Peralatan tenun yang dipergunakan adalah alat tenun tradisional yaitu alat tenun gedongan.

Dengan peralatan sederhana, kainkain Timor dibuat untuk dikenakan dalam 
upacara-upacara daur kehidupan, upacara pendirian sebuah rumah, masa setelah panen, sampai upacara penguburan atau upacara kematian. Seperti halnya upacara kematian di Timor memerlukan sejumlah banyak kain untuk upacara kematian seorang tokoh adat atau raja diperlukan seratus lima puluh kain adat, baik untuk dikuburkan bersama orang yang meninggal maupun untuk dibagi-bagikan. Selain dalam upacara kematian, kain ini memegang peranan penting yaitu sebagai mas kawin dalam upacara perkawinan. Bahkan di antara berbagai suku di wilayah Timor sendiri termasuk wilayah Timor bagian Timur, ada jenis kain Timor yang khususnya bercorak motif patola mempunyai nilai tukar yang mempererat persatuan di antara mereka yang berbeda adat istiadatnya.

\section{Hasil dan Pembahasan}

Penciptaan karya ini menghasilkan bentuk motif yang ada pada kain Tais ke busana batik.pembuatan busana ini menggunakan beberapa teknik sebagai pemuncul bentuk ornament dan motif. Motif yang diterapkan pada batik ini adalah motif-motif kain Tais Timor yang telah dipilih sebagai sumber ide penciptaan. Penerapan teknik menggunakan teknik batik.

\section{Proses Perwujudan}

Proses perwujudan merupakan suatu tahap pengerjaan karya dari langkah awal hinga akhir. Untuk memperlancar dan memperoleh hasil yang maksimal dalampembuatan karya busana pesta, langkah selanjutnya yang harus di tempuh adalah menentukan bahan dan alat yang digunakan, teknik pengerjaan, dan tahap perwujudan.
Bahan dan Alat

Bahan

a. Kain mori atau kain primasima Merupakan kain mori yang paling halus dan biasanya digunakan untuk membatik jenis batik tulis yang sangat halus. Mori ini biasanya dalam bentuk gulungan (piece) dengan lebar 1,06 $\mathrm{m}$ dan panjang 15,5 m. Susunan atau konstruksi primissima menggunakan benang Ne 50-56. Kepadatan (tetel) benang untuk lusi antara 105-125 per inch(42-50 per $\mathrm{cm}$ ) dan untuk pakan antara 100-120 per inch (42-50 per $\mathrm{cm}$

b. Kain tulle, Kain tulle atau yang biasa disebut dengan kain tille adalah kain yang ringan yang berbentuk seperti jala dengan lubang kecil. Kain tulle dibuat dari berbagai macam serat seperti sutra, nilon, dan rayon. Kain tulle biasanya digunakan untuk kerudung, detail aksesoris, gaun, dan kostum ballet. Kain tulle dapat memberikan kesan feminin bagi pemakainya..

c. Kain Brokat

Brokat bukanlah bahan renda (lace), bukan pula embroidery atau kain lainnya. Brokat merupakan jenis kain yang kaya akan dekorasi, seringkali dibuat menggunakan sutra berwarna, dengan atau tanpa benang emas dan perak. Karakteristik bahan ini keras dan gatal jika tersentuh kulit, maka harus ada bahan pelapis di bagian dalam brokat untuk memberi kesan nyaman bagi pemakai.

d. malam atau lilin, adalah bahan yang digunakan untuk menutup permukaan kain menurut gambar motif batik, sehingga permukaan kain yang tertutup tersebut menolak resist terhadap warna yang diberikan pada kain tersebut. Lilin batik ini tidak terdiri dalam satu macam bahan, tetapi campuran dari beberapa pokok lilin. 
Sebagai bahan pokok lilin adalah: Gondorukem, Damar matakucing, Parafin, Microwax, Minyak kelapa, dan lerak.

e. Naptol dan Indigosol

Pewarna sintetis/buatan. Merupakan pewarna yang dapat digunakan dalam suhu yang tidak merusak lilin, yang termasuk golongan pewarna tersebut adalah: indigo, indigosol, naptol dan rapid yang diguanakan untuk mewarnai kain dengan cara mencelup atau mencolet pada bagianbagian tertentu sedangkan dan asam sulfat atau hcl digunakan untuk membangkitkan warna indigosol serta mengucinya agar tidak warna tidak luntur.

\section{Alat}

a.Canting

Canting berfungsi semacam pena, yang diisi lilin malam cair sebagai tintanya. Bentuk canting beraneka ragam, dari yang berujung satu hingga beberapa ujung.

Canting yang memiliki beberapa ujung berfungsi untuk membuat titik dalam sekali sentuhan. Sedangkan canting yang berujung satu berfungsi untuk membuat garis, lekukan dan sebagainya. Canting terdiri dari tiga bagian. Pegangan canting terbuat dari bambu. Terdapat mangkuk sebagai tempat lilin malam, serta ujung yang berlubang sebagai ujung pena tempat keluarnya lilin malam, ada beberapa macam canting yang digunakan yaitu canting klowong, isen dan tembok.

b. wajan dan kompor

Sebelum digunakan, lillin malam harus dicairkan terlebih dahulu dengan cara dipanaskan di atas kompor dan wajan. Kompor yang digunakan biasanya terbuat dari besi, tanah atau kompor listrik.
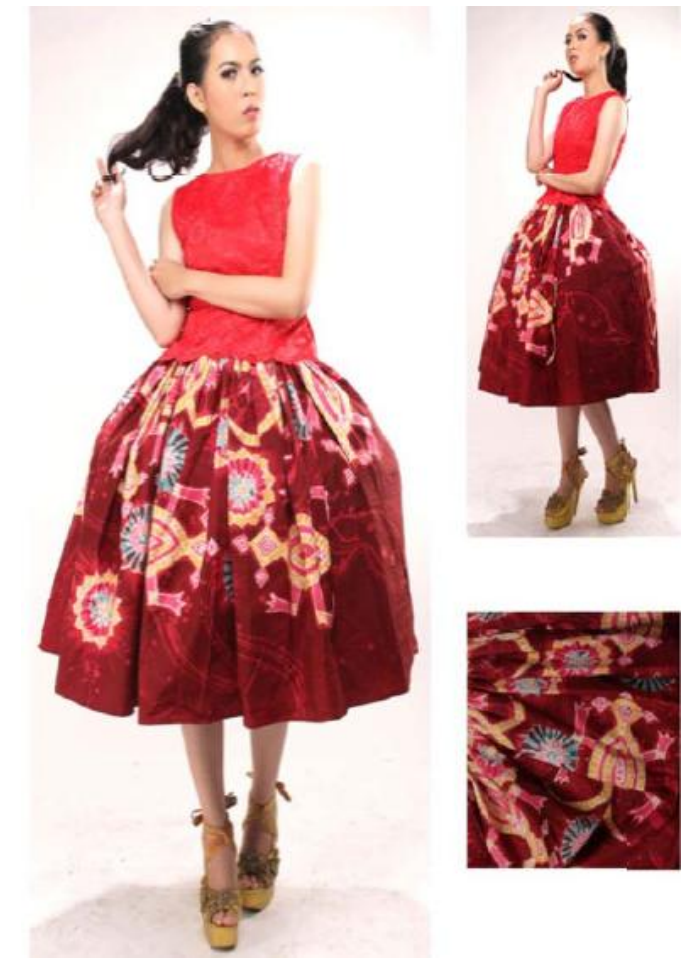

Karya 1

Judul : Menina Do Crocodilo

Media: kain prima asima.

Tahun: 2015, Photog grafer: santos

Model: Enda
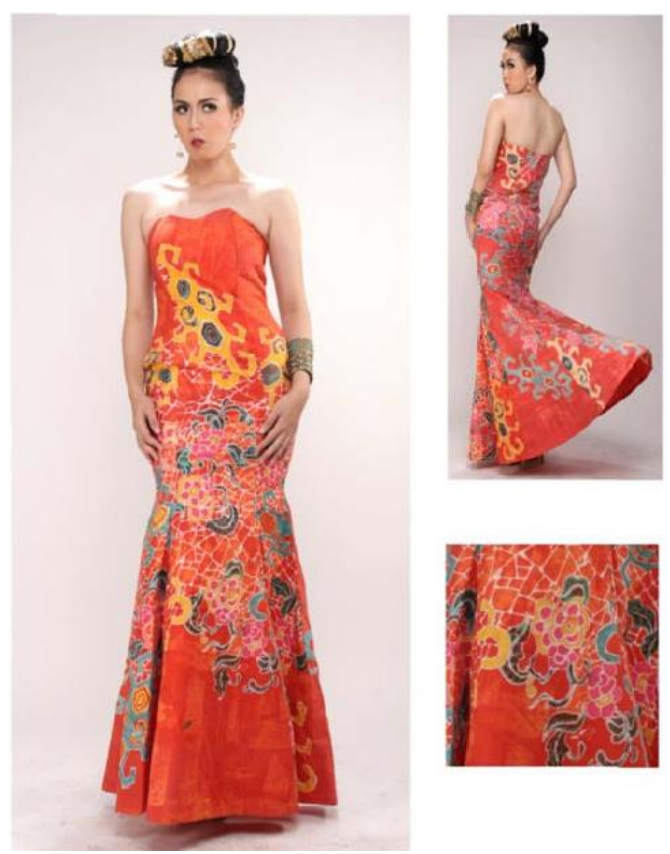

Karya 2

Judul : Princes da Raices

Media: kain prima asima.

Tahun: 2015, Photog grafer: santos

Model: Enda
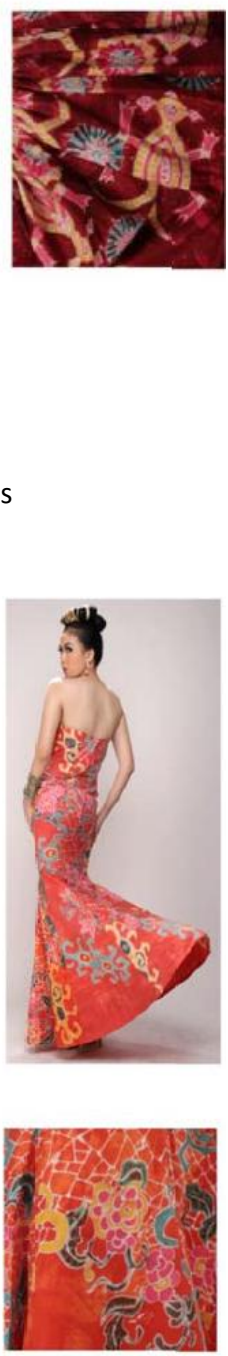

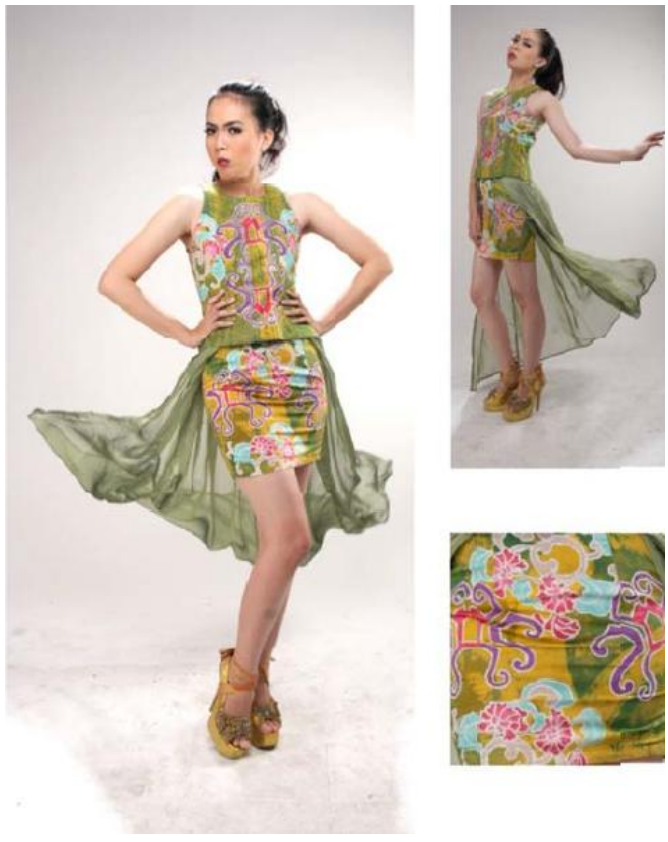

Karya 3

Judul : Senhora da Cultura

Media: kain prima asima.

Tahun: 2015, Photog grafer: santos Model: Enda
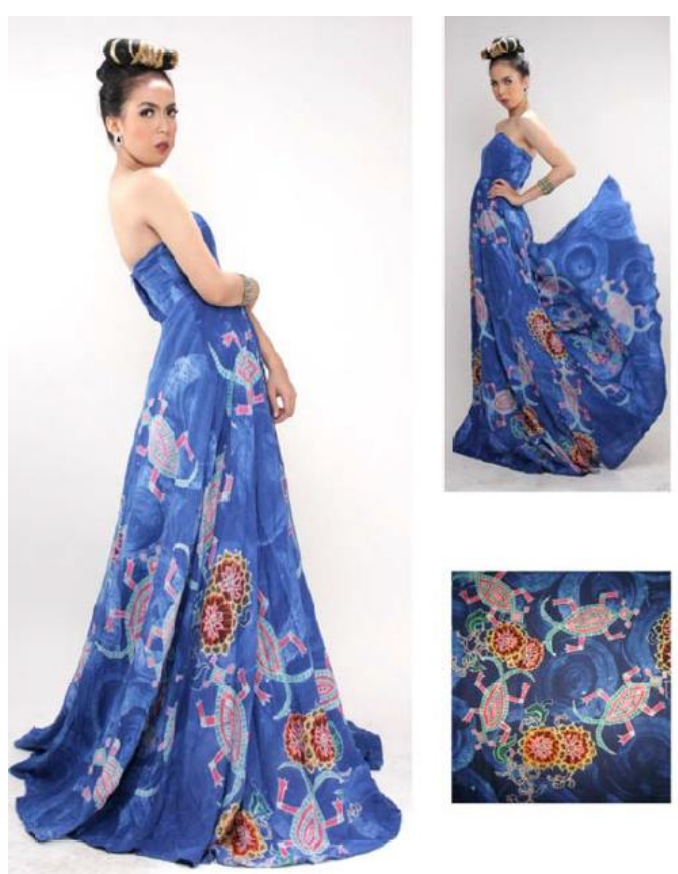

Karya 4

Judul : Rainha da Leste

Media: kain prima asima.

Tahun: 2015, Photog grafer: santos

Model: Enda

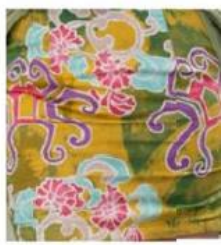

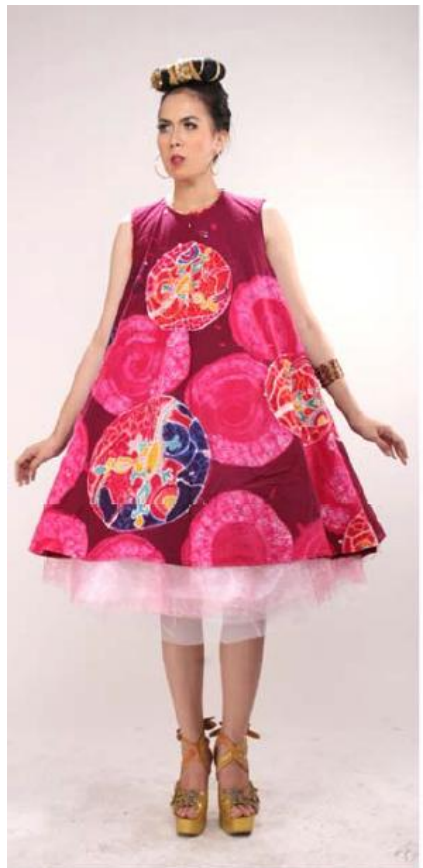

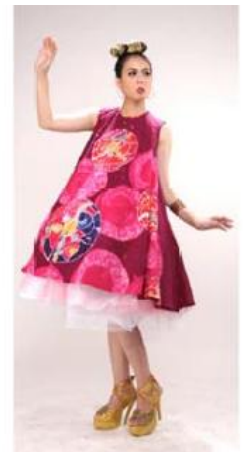

Karya 5

Judul : Amor Semlimite

Media: kain prima asima.

Tahun: 2015, Photog grafer: santos

Model: Enda
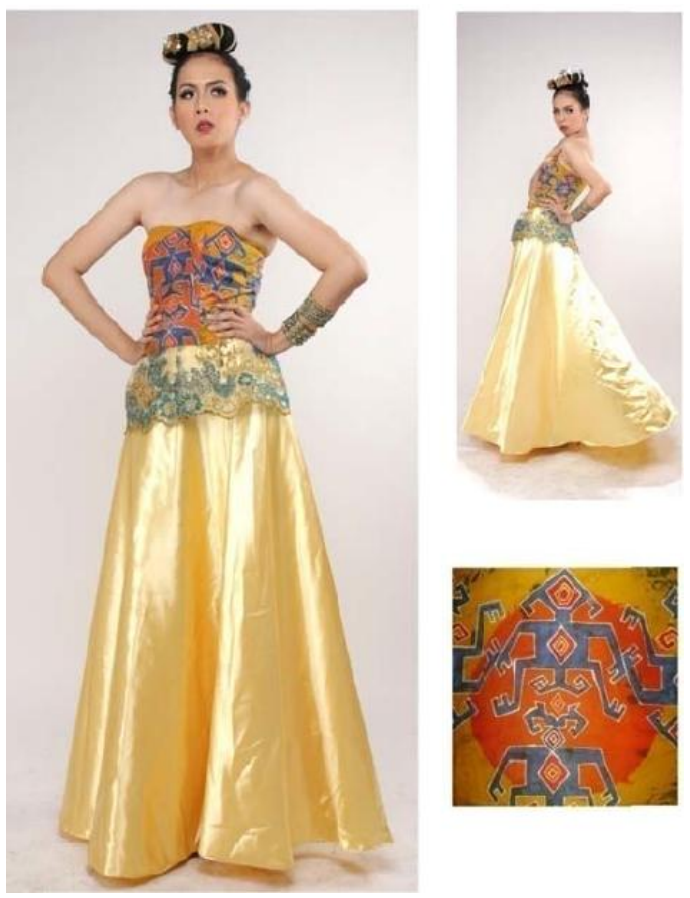

Karya 6

Judul : Umane

Media: kain prima asima.

Tahun: 2015, Photog grafer: santos

Model: Enda 

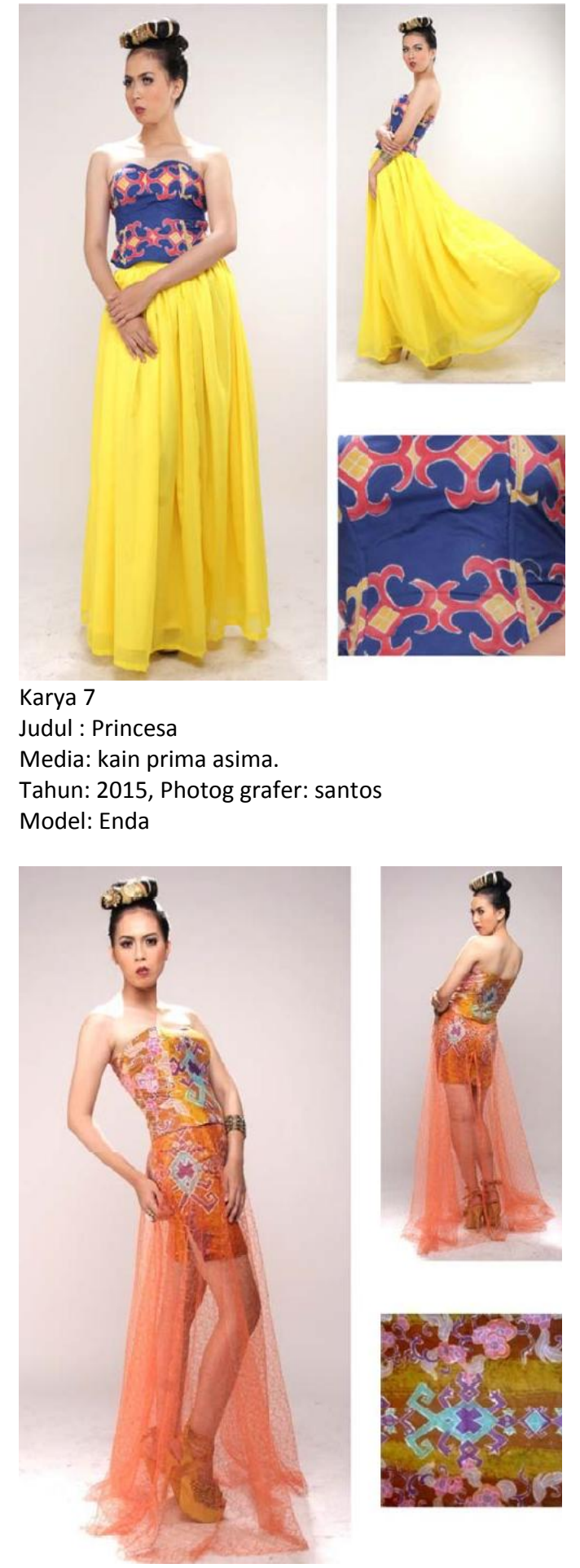

Karya 8

Judul : Menina da Agrikultura Media: kain prima asima.

Tahun: 2015, Photog grafer: santos Model: Enda
Setiap karya yang diciptakan memiliki karate yang berbeda-beda. Karakter pada karya dapat dilihat dari bentuk karya yang bervariasi.Karya yang terdiri dari bermacam bentuk seperti blus dan bustier dengan rok panjang, rok pendek, dres.

Pada dasarnya di setiap karya ini menampilkan unsur budaya yang ada pada motif kain Tais yang dipadukan ke busana pesta. Setiap busana pesta dimodifikasikan sesuai selera kaum muda tetapi masih menampilkan beberapa bentuk dan tradisinya. Selain menampilkan karakter penciptanya karya ini juga memberikan kesan simbolik pada pemakai berdasarkan bentuk bajunya. Bentuk baju dibuat dengan makna tertentu yang menggunakan kesan cantik, elegan, dan anggun.

\section{Kesimpulan}

Demikian karya-karya yang diciptakaan dengan proses dan tahap yang panjang dari awal sampai akhir. Beberapa permasalahan timbul saat proses berlangsung antara lain. Saat pewarnaan batik yang harus diulangulang untuk mendapatkan warna yang diinginkan. Pembuatan aplikasi pili yang membutuhlan ketelatenan dan waktu yang panjang dalam proses penyelesaiian tugas akhir ini. Adanya solusi-solusi saat berlangsungnya proses pengerjaan pada akhirnya semua permasalahan dengan hasil yang cukup puas. Akan tetapi dengan proses yang telah dilakukan pastilah ada beberapa kekurangaan dan dengan adanya saran, masukan dan tambahan ilmu, maka 
hal tersebut akan dapat menjadi

pertimbangan dalam proses berkarya selanjutnya.

\section{Daftar Pustaka}

Anton H. Bekker,metode-metode Filsafat, 1886

Cita Tenun Indonesia, Tenun Hendwoven Textiles Of Indonesia, 2011

Dra.Suwati Kartika, Tenun Ikat Indonesia Ikats, 1987

Dharsono Sony Kartika 2007

Joana Barrkman, casa Europa, the at of futus from light to dark,Timor-Leste,

Joanna Barrkman, Husi Bei Ala Timor Rira Nia Liman, 2009

Poerwadarminta, W. J.S,1987:17

SP. Gustami, Nukilan Seni Ornamen Indonesia, yogakarta, 2008. 